\title{
Corrigendum: High-throughput oncogene mutation profiling in human cancer
}

Roman K Thomas, Alissa C Baker, Ralph M DeBiasi, Wendy Winckler, Thomas LaFramboise, William M Lin, Meng Wang, Whei Feng, Thomas Zander, Laura E MacConnaill, Jeffrey C Lee, Rick Nicoletti, Charlie Hatton, Mary Goyette, Luc Girard, Kuntal Majmudar, Liuda Ziaugra, Kwok-Kin Wong, Stacey Gabriel, Rameen Beroukhim, Michael Peyton, Jordi Barretina, Amit Dutt, Caroline Emery, Heidi Greulich, Kinjal Shah, Hidefumi Sasaki, Adi Gazdar, John Minna, Scott A Armstrong, Ingo K Mellinghoff, F Stephen Hodi, Glenn Dranoff, Paul S Mischel, Tim F Cloughesy, Stan F Nelson, Linda M Liau, Kirsten Mertz, Mark A Rubin, Holger Moch, Massimo Loda, William Catalona, Jonathan Fletcher, Sabina Signoretti, Frederic Kaye, Kenneth C Anderson, George D Demetri,

Reinhard Dummer, Stephan Wagner, Meenhard Herlyn, William R Sellers, Matthew Meyerson \& Levi A Garraway

Nat. Genet. 39, 347-351 (2007); published online 11 February; corrected after print 14 March 2007

In the version of this article initially published, the name of an author was spelled incorrectly as Laura MacConnaill. The correct spelling is Laura MacConaill. The error has been corrected in the HTML and PDF versions of the article.

\section{Corrigendum: Cross-talk and decision making in MAP kinase pathways}

Megan N McClean, Areez Mody, James R Broach \& Sharad Ramanathan

Nat. Genet. 39, 409-414 (2007); published online 28 January; corrected after print 14 March 2007

In the version of this article initially published, the strain referred to as FUS3 ${ }^{\mathrm{D} 63 \mathrm{~S}}$ on pp. $411-412$ of the main text and in the figure legend for Figure $\mathbf{5} \mathbf{c}-\mathbf{f}$ should instead read FUS3 ${ }^{\mathrm{D} 317 \mathrm{G}}$. The error has been corrected in the PDF version of the article.

\section{Corrigendum: A common CFH haplotype, with deletion of CFHR1 and} CFHR3, is associated with lower risk of age-related macular degeneration

Anne E Hughes, Nick Orr, Hossein Esfandiary, Martha Diaz-Torres, Timothy Goodship \& Usha Chakravarthy

Nat. Genet. 38, 1173-1177 (2006); published online 24 September 2006; corrected after print 14 March 2007

In the version of this article initially published, the $\mathrm{G}$ and $\mathrm{A}$ alleles of rs 1831281 in Figure 1 should be reversed, and the block 2 haplotypes in Figure 1 , Table 2 and Supplementary Table 2 should be corrected to 1:AGGCGACG, 2:AGGCGAAG, 3:GTGCGGAG, 4:GTATGAAA and 5:GTGTAAAG. The error has been corrected in the HTML and PDF versions of the article.

\section{Corrigendum: Genome variation and evolution of the malaria parasite} Plasmodium falciparum

Daniel C Jeffares, Arnab Pain, Andrew Berry, Anthony V Cox, James Stalker, Catherine E Ingle, Alan Thomas, Michael A Quail, Kyle Siebenthall, Anne-Catrin Uhlemann, Sue Kyes, Sanjeev Krishna, Chris Newbold, Emmanouil T Dermitzakis \& Matthew Berriman Nat. Genet. 39, 120-125 (2007); published online 10 December 2006; corrected after print 8 February 2007

In the original version of this paper, the authors failed to acknowledge that sequencing of the $P$. falciparum IT laboratory isolate was funded by a European Union 6th Framework Program grant to the BioMalPar Consortium (contract number LSHP-LT-2004-503578). This error has been corrected in the PDF version of the article. 